\title{
CONTENTS OF BIORHEOLOGY, VOLUME 30, NUMBERS 5/6
}

\author{
P. Verdugo \\ P. Verdugo
}

J. F. Stoltz

M. Goto, A. Kimura, K. Tsujioka and F. Kajiya

T. M. Griffith and D. H. Edwards

Y.J. Lim, S. Nanto, T. Masuyama and M. Hori

M. Kitakaze, M. Hori, S. Takashima, T. Morioka, T. Minamino, H. Sato,

Y. Okazaki, M. Inoue and T. Kamada

T. Komaru, H. Kanatsuka, K. Dellsperger and T. Takishima

P. Sipkema, P. J. W. van der Linden and 381 N. Westerhof

C. Oddou and A. Razakamiadana iii Editorial

v Obituary

Alex Silberberg: The Sower

Conference Communications Proceedings of the Eighth International Congress of Biorheology, Yokohama City, Japan, 3-8 August 1992

Plenary Lecture

305 New trends in biorheology

Part II

Symposium: Biorheology in Coronary Circulation

323 Characteristics of coronary artery inflow and its significance in coronary pathophysiology

333 Mechanisms underlying chaotic vasomotion in isolated resistance arteries: Roles of calcium and EDRF

349 Subendocardial myocardial ischemia as assessed with myocardial contrast echocardiography in patients with ischemic heart diseases

359 Superoxide dismutase enhances both adenosine release and coronary hyperemic flow through protection of 5 -nucleotidase against its degradation during reperfusion following ischemia in dogs

371 The role of ATP-sensitive potassium channels in regulating coronary microcirculation

381 Vasoactive properties of rat coronary artery: In the tissue and isolated

387 Mechanical compression of small coronary vessels during the cardiac cycle 
G. B. Nash and W. B. Gratzer

J. E. Gomez and G. B. Thurston

T. Taylor, H. Okino and T. Yamaguchi

T. Matsumoto, M. Kawai and T. Masuda

G. Cloutier and K. K. Shung

E. Donath, T. Pomorski and

V. F. Pastushenko

G. I. Zahalak

\section{Review Article}

397 Structural determinants of the rigidity of the red cell membrane

Papers

409 Comparisons of the oscillatory shear viscoelasticity and composition of pathological synovial fluids

429 The effects of supravalvular aortic stenosis on realistic three-dimensional left ventricular blood ejection

435 Rheological properties and fractal structure of concentrated polyion complexes of chitosan and alginate

443 Study of red cell aggregation in pulsatile flow from ultrasonic Doppler power measurements

463 On the lateral distribution of spicula on echinocytes

Brief Communication

471 On the ambiguity of viscoelastic-fluid representations of cytoplasm subjected to large deformations

473 Erratum

475 Contents of Clinical Hemorheology, Volume 13, Number 3

I Contents Index, Volume 30, 1993

V Author Index, Volume 30, 1993 